\title{
Having and Being a Personal Physician: Vision of the Pisacano Scholars
}

\author{
Jennifer E. DeVoe, MD, DPhil, Terri Nordin, MD, Kristen Kelly, MD, \\ Marguerite Duane, MD, MHA, Sarab Lesko, MD, MPH, Saria Carter Saccocio, MD, \\ and Lenard I. Lesser, MD
}

Having a strong relationship with a personal physician can improve patient health outcomes. Yet achieving and sustaining this type of patient-physician relationship is often not possible in the current American health care system. Pisacano scholars and alumni, a group of young physician leaders supported by the American Board of Family Medicine, gathered for a 2-day symposium in June 2010 to explore the meaning of personal doctoring and its importance to our work as family physicians. Using the techniques of appreciative inquiry, the group discussed three questions: What is it like to bave a personal physician? What is it like to be a personal physician? and, What are some feasible next steps toward making this possible? Symposium participants concluded that achieving the ideal patient-physician relationship for all patients and physicians would involve extensive alterations to the current health care system beyond what is outlined in the 2010 Patient Protection and Affordable Care Act. However, in the context of current health reform efforts, individual physicians, researchers, and policy makers must not lose sight of the importance of the patientphysician relationship and should continue to take concrete steps on an individual and system level to move us closer to this ideal. (J Am Board Fam Med 2011;24:463-468.)

Keywords: Continuity of Patient Care, Family Medicine Career Choice, Health Systems/Services, One-On-One Patient Care, Physician Patient Interaction

"A person in difficulties wants in the first place the help of another person on whom he can rely as a friend-someone with knowledge of what is feasible but also with good judgment on what is desirable in the particular circumstances and an understanding of what the circumstances are. The more complex medicine becomes, the stronger are the reasons why everyone should have a personal doc-

This article was externally peer reviewed.

Submitted 9 December 2010; revised 13 February 2011; accepted 22 February 2011.

From the Department of Family Medicine, Oregon Health and Science University, Portland (JED); Department of Family and Community Health, University of Medicine and Dentistry of New Jersey-Robert Wood Johnson Medical School, New Brunswick (TN); Department of Family Medicine, University of Washington, Seattle (KK); Spanish Catholic Center of Catholic Charities, Washington, DC (MD); Center for Researching Health Outcomes, Mercer Island, WA (SL); Danville Regional Medical Center, Danville, VA (SCS); and the Robert Wood Johnson Clinical Scholars Program, Departments of Medicine and Family Medicine, University of California, Los Angeles (LIL).

Funding: none.

Conflict of interest: none declared. tor who will take continuous responsibility for him, and, knowing how he lives, will keep things in proportion" (p. 752). ${ }^{1}$

-TF Fox in The Lancet, 1960

The passage of the Patient Protection and Affordable Care Act has focused the nation's attention on well-documented issues surrounding access to health care services, the quality of care delivered, and the rising costs of care. ${ }^{2-8}$ Innovative changes in systems of care delivery, such as the patient-

Disclaimer: All 25 Pisacano Scholars participating in the Jackson Hole Personal Doctoring Annual Meeting contributed to this article, including Alana Benjamin, Cheng-Chieh Chuang, Jennifer DeVoe, Marguerite Duane, Bethany Enoch, Pamela Ferry, Rachel Friedman, Kenneth Grimm, Derek Jackson, Kristen Kelly, Anne Kolan, Brian "Yoshi" Laing, Sarah Lesko, Lenard Lesser, Anthony Lim, Jim Little, Kristine McCoy, Amy McIntyre, Terri Nordin, Gary Plant, Jamie Reedy, John Raser, David Rider, Saria Saccocio, and Olga Valdman.

Corresponding author: Jennifer E. DeVoe, Department of Family Medicine, Oregon Health and Science University, 3181 Sam Jackson Park Rd., mailcode: FM, Portland, OR 97239 (E-mail devoej@ohsu.edu). 
centered medical home and the patient-centered primary care collaborative, have shown early promise. $^{9-18}$ Though such systems-based changes are essential for improving the quality of health care delivered in the United States, ${ }^{19-21}$ the sustained relationship between one physician and one patient, as described by Fox in $1960,{ }^{1}$ has not been a central focus in many of the proposed changes. This concerning shift away from one of the fundamental tenets that attracted many of us to family medicine prompted a group of Pisacano scholars and alumni to gather together to explore what it means to be a personal physician and what can be done to ensure that this relationship remains at the center of health care reform efforts.

The Pisacano Leadership Foundation was founded by the American Board of Family Medicine (ABFM) in honor of Nicholas Pisacano, founding director of the ABFM, to identify leaders among medical students entering family medicine and to offer this group unique opportunities for leadership training and networking. Pisacano scholars are selected at the end of medical school and given financial support through residency but are able to maintain their relationship with the group throughout their careers. Twenty-five Pisa- cano scholars and alumni (11 who were in the final year of medical school or in residency and 14 who had completed residency) gathered in Jackson Hole, Wyoming, in June 2010 for a 2-day series of facilitated discussions centered around the theme, What Could Revolutionary Personal Doctoring Look Like in 2020? Table 1 describes basic sociodemographic characteristics of this subgroup of 25 scholars compared with all 96 Pisacano scholars and alumni.

Using steps from a process called appreciative inquiry, ${ }^{22-24}$ the group recalled and shared stories and peak experiences of personal doctoring. In small groups, participants imagined how their personal practices of medicine and the overall health care system could be reformed to support and sustain crucial elements of relationship-centered care. ${ }^{25-30}$ The group discussed helpful examples of actual health care innovations from around the country after hearing presentations of work being done by participants in their individual practice settings.

After the first day of discussions, the group crafted 3 questions to guide further discussion: (1) What is it like to bave a personal physician? (2) What is it like to be a personal physician? (3) What are some feasible next steps, both personal and

Table 1. Characteristics of the 25 Pisacano Scholars and Alumni Who Participated in the Jackson Hole Conference on Personal Doctoring Compared With All 96 Pisacano Scholars and Alumni

\begin{tabular}{|c|c|c|}
\hline Participant Characteristics & $\begin{array}{l}25 \text { Pisacano Scholars and } \\
\text { Alumni at Jackson Hole } \\
\text { Conference (n [\%]) }\end{array}$ & $\begin{array}{c}96 \text { Pisacano Scholars and } \\
\text { Alumni (as of February 2011) } \\
\text { (n [\%]) }\end{array}$ \\
\hline \multicolumn{3}{|l|}{ Age (years) } \\
\hline$<30$ & $6(24)$ & $15(16)$ \\
\hline $31-35$ & $8(32)$ & $19(20)$ \\
\hline $36-40$ & $4(16)$ & $27(28)$ \\
\hline$>40$ & $7(28)$ & $35(36)$ \\
\hline \multicolumn{3}{|l|}{ Residency completion } \\
\hline Currently in medical school or residency & $9(36)$ & $21(22)$ \\
\hline Completed residency $\leq 5$ years ago & $7(28)$ & $22(23)$ \\
\hline Completed residency $>5$ years ago & $9(36)$ & $53(55)$ \\
\hline \multicolumn{3}{|l|}{ Medical school graduation year } \\
\hline 2010 or 2011 & $3(12)$ & $12(13)$ \\
\hline 2005-2009 & $12(48)$ & $23(24)$ \\
\hline 2000-2004 & $4(16)$ & $25(26)$ \\
\hline 1994-1999 & $6(24)$ & $36(37)$ \\
\hline \multicolumn{3}{|l|}{ Geographic residence } \\
\hline Northeast & $7(28)$ & $19(20)$ \\
\hline Midwest & $5(20)$ & $20(21)$ \\
\hline South & $1(4)$ & $17(18)$ \\
\hline West & $12(48)$ & $40(42)$ \\
\hline
\end{tabular}




\section{Table 2. What Is It Like To Have a Personal Physician?}

- Comfortable, intimate relationship, like family or friend.

- Trust, confidence, security; having a go-to person.

- You are known. You don't have to retell your story. You are the exception to the guideline. You and your life's context are important.

- You have an advocate, navigator, coordinator for the "confusing and frightening" health care system-someone who follows up with specialists.

- Convenient access (via office visit, phone, E-mail).

- Shared decision making and mutual respect.

- Knowledgeable, both in terms of personal knowledge of the patient and book knowledge.

- Coach for preventive care/overall well-being.

- Part of a health care team.

collective, toward making the resulting vision of personal doctoring a reality? From the experience of being patients, participants felt that having a personal physician meant being in a relationship that was comfortable and intimate; being in a relationship with trust, confidence, and security; feeling known as a person; and having an advocate, someone to help navigate the health care system. A full list of responses can be found in Table 2.

From the experience of serving as family physicians across the country, the groups felt that being a personal physician involved knowing your patient's context and story; feeling rewarded and inspired by the role; and working collaboratively with patients to achieve shared decision making. This professional role was also perceived to be challenging in that it can be draining and difficult to balance with personal roles and responsibilities. Table 3 includes the full list of responses.

Table 4 summarizes "what are feasible next steps, both personal and collective, toward making our vision of personal doctoring a reality?," includ- ing the need to restructure the payment system to support and reward the work of relationship building; improved use of technology to facilitate communication; increased time with patients and decreased panel sizes; improved access to care; and more focus on teams and other workflow redesign to support care coordination and advocacy and avoid burn-out. One issue not addressed in any current reform efforts was one of assisting physicians in maintaining work-life balance, which was discussed as a barrier to being an effective personal physician and avoiding burn-out.

On a more individual level, the group also identified ways in which each person could become better personal doctors, including putting personal emphasis on the relationship with patients, participating in regular self-assessment and self-reflection; and increasing community involvement to improve knowledge of patients outside of the clinic. This group of young physician leaders acknowledged the additional personal responsibility this would entail and recognized that, in many cases, being a personal doctor requires specific personal commitments to community, to self-assessment, and to focusing on the doctorpatient relationship.

Symposium participants concluded that achieving the ideal patient-physician relationship for all patients and physicians would involve extensive reforms beyond what is outlined in the 2010 Patient Protection and Affordable Care Act. The group also acknowledged that instituting such comprehensive system reforms that emphasize the role of the personal physician would be extremely difficult. However, initial steps might include a set of rewards or penalties for measures that emphasize the central role of the personal physician. Examples might include:

\section{Table 3. What Is It Like To Be a Personal Physician?}

\begin{tabular}{ll}
\hline Ideals & You know your patients' context and story. You have a committed relationship and invest in patients. \\
& - You are rewarded and inspired by this professional role. You feel a sense of calling. You enjoy it. \\
- Meeting patient needs; not focused on tests or insurance. \\
- An advocate for patients' health. A guide, navigator, negotiator, coordinator of health care. \\
- Community participant and contributor. \\
- Work can be draining - can't be there $24 / 7$, need team. \\
- Cannot always provide care in appropriate setting/not enough flexibility to offer care via E-mail, phone, etc. \\
- Never enough time with patients to address all concerns and get to know each other.
\end{tabular}


System and practice-level changes

Individual-level changes: "One thing I'm going to do now."
- Restructure payment systems to better support work done outside the exam room and not face-to-face (E-mails, phone calls), mental health care, coordination of care, long-term continuous relationships. Incentivize relationship building.

- Use electronic medical records and other technology to facilitate communication and to improve rather than detract from relationships.

- Build team, restructure clinic work flow.

- Educate patients and the public about the feasibility and value of having a personal physician and the need for advocacy for system change to make this widely possible.

- Appropriately sized (smaller) patient panels.

- Change medical school education-teach trainees to ask for patient's perspective.

- More actively coordinate care and avoid redundant and wasteful care.

- Add personal touches (eg, attend funerals, send birthday cards).

- Put the focus back on the relationship. Ask patients at least one non-health care question about hobbies, family, etc.; ask about personal goals; take social histories; listen longer in the beginning.

- Self-assessment and self-reflection: Ask self: "When am I my patient's doctor? Am I the type of doctor I want for myself and family?" Recommit to being a personal physician.

- Teach residents to ask for patient perspective.

- Make sure patients know their team and use their team.

- Assess how electronic medical records and other technologies are helping or hindering patient relationships.

- Create price lists and post them.

- Increase involvement in the community; build flexibility into schedule for community involvement.
- Reduced or no payments for hospitalization if a patient's personal physician is not contacted within 24 hours of admission and/or if the patient is discharged without direct communication with the personal physician.

- Mandates to ensure that insurance companies provide their members access to a continuous relationship with a personal physician and ensure there are standardized ways to objectively measure this mandated access.

- Automatic systems to facilitate communication between pharmacies and the personal physician when a patient fills prescriptions not written by the personal physician.

- A requirement that all licensed electronic health record systems prominently display the name and correct contact information of a patient's current personal physician.

Whether the system takes small steps such as those listed above or the larger steps required to ensure that relationship-centered care remains at the core of health care delivery in the United
States, the importance of personal doctoring cannot be underestimated. A growing body of research indicates that having a personal physician, an individual that a patient identifies as his or her doctor, is a potential marker for improved access to care, sometimes more so than the presence or absence of insurance. ${ }^{31}$ The strength of a patientphysician relationship is directly related to improving care quality. Gaining a better understanding of how the physician-patient relationship affects health may provide insights into how to eliminate disparities in health care in the United States. ${ }^{31}$ Shared decision making, now endorsed as a preferred method of medical decision making by major medical organizations, requires a longstanding relationship between a physician and a patient that allows both parties to understand the values and biases of the other. ${ }^{32}$ One perspective on the patient-centered medical home might emphasize information technology, altered financial incentives in primary care, and practice redesign as the most important elements needed to build medical homes. On the other 
hand, we cannot lose sight of the crucial importance of "continuous healing relationships" and of "developing measures of care that reflect experience and relationships rather than infrastructure and processes" (p. 2039). ${ }^{9}$ In other words, though rethinking the structure and processes in medical care is undeniably essential, relationships must remain at the core of medicine and healing.

Every practicing primary care physician can recall key moments in which he or she connected with patients in particularly important ways. These are the moments that live with providers throughout their careers and maintain their passion for medicine. The desire to experience these moments-when physicians act as personal physicians-often inspires new physicians to choose careers in primary care, in which continuity and relationships purportedly are paramount.

The concepts and concerns discussed in this article, which emerged from a thoughtful and reflective process within a group designated by the $\mathrm{ABFM}$ as emerging leaders in family medicine, echo voices from the past. For example, in 1965, Gayle Stephens wrote, "One of the paradoxes of our time is that the healing relationship seems most in jeopardy at a time when we need it most. There are more forces which threaten to depersonalize the meeting of a doctor and patient.... Health is not a commodity that can be purchased in any quantity as long as one has the money. One can buy the mechanical appurtenances of healing but one cannot buy that essential ingredient-a physician who really cares about the patient" (p. 242). ${ }^{33}$ The thoughts reflecting long-standing definitions of personal doctoring outlined in this commentary are not new; the importance of this commentary lies in the fact that this group of young leaders recognized the importance of spending time to renew visions of personal doctoring and felt compelled to write about it here. The process reinforced for the group that personal doctoring is central to the health of our population and that the patient-centered medical home and other system reform efforts may be necessary for, but are not synonymous with, personal doctoring. Furthermore, these efforts might weaken, rather than strengthen, a physician's ability to achieve lasting and meaningful relationships with patients.

Those undertaking reform must consciously focus on research and policies designed to foster the development of patient-physician relationships; if they do not, the system perhaps will run more efficiently and data will be more easily accessible, but patients may still receive suboptimal care and primary care physicians may continue to experience burnout at high rates. The relationship between a patient and a physician is more than a prescription, a diagnosis, or a procedure, no matter how cheaply, efficiently, or accurately delivered. Dr. Loxterkamp ${ }^{34}$ once wrote, "They [patients] are more than the sum of their episodic illnesses or a case number in the registry of chronic disease. Like me, they are looking for purpose and connection in their lives" (p. 18). This group of physician leaders offers that, in the context of current health reform efforts, all family physicians should prioritize having similar dialogues, both among themselves and with patients, about how to nurture the purpose and connection inherent in personal doctoring.

We are grateful to the American Board of Family Medicine and the Pisacano Leadership Foundation for their support of the Pisacano Scholars Program and this project. Robert Cattoi, Trish Palmer, and Jane Ireland provided important instrumental support for this project and guidance throughout our scholarship and beyond.

Kurt Stange helped to plan the conference, facilitated our group process and guided the analysis of the data and writing of this paper. Heide Aungst and Mary Ruhe served as outside auditors and analysts and identified the initial themes.

\section{References}

1. Fox TF. The personal doctor and his relation to the hospital: observations and reflections on some American experiments in general practice by groups. Lancet $1960 ; 1: 743-60$.

2. Institute of Medicine, Committee on Quality of Health Care in America. Crossing the quality chasm: a new health system for the 21st Century. Washington, DC: National Academy Press; 2001.

3. Institute of Medicine. Unequal treatment: confronting racial and ethnic disparities in healthcare. Washington, DC: The National Academies Press; 2003.

4. Institute of Medicine. Informing the future. Critical issues in health. 2nd ed. Washington, D.C.: National Academies Press; 2003.

5. Institute of Medicine. Insuring America's health: principles and recommendations. Washington, DC: National Academies Press; 2004.

6. Institute of Medicine. The Unequal Burden of Cancer: An Assessment of NIH Research and Programs 
for Ethnic Minorities and the Medically Underserved. Washington D.C.: National Academies Press; 1999.

7. Congressional Budget Office. The long-term outlook for health care spending. Available at: http://www.cbo.gov/ ftpdocs/87xx/doc8758/11-13-lt-health.pdf. Accessed 29 November 2010.

8. Daniels N, Saloner B, Gelpi AH. Access, cost, and financing: achieving an ethical health reform. Health Aff (Millwood) 2009;28(5):w909-16.

9. Rittenhouse DR, Shortell SM. The patient-centered medical home: will it stand the test of health reform? JAMA 2009;301(19):2038-40.

10. Nutting PA, Miller WL, Crabtree BF, Jaén CR, Stewart EE, Stange KC. Initial lessons from the first national demonstration project on practice transformation to a patient-centered medical home. Ann Fam Med 2009;7:254-260.

11. Bodenheimer T, Pham HH. Primary care: current problems and proposed solutions. Health Aff (Milwood) 2010;29(5):799-805.

12. Crabtree BF, Nutting PA, Miller WL, Stange KC, Stewart EE, Jaén CR. Summary of the National Demonstration Project and recommendations for the patient-centered medical home. Ann Fam Med 2010;8(Suppl 1):S80-S90.

13. Patient-Centered Primary Care Collaborative. PCPP pilot guide: proof in practice. A compilation of patientcentered medical home pilot and demonstration projects. 2009:90. Available at: http://www.pcpcc. net/files/PilotGuidePip.pdf. Accessed 18 May 2011.

14. Stange KC, Nutting PA, Miller WL, et al. Defining and measuring the patient-centered medical home. J Gen Int Med 2010;25(6):601-12.

15. Stange KC, Miller WL, Nutting PA, Crabtree BF, Stewart EE, Jaén CR. Context for understanding the National Demonstration Project and the patient-centered medical home. Ann Fam Med 2010;8(Suppl 1): S2-S8.

16. Miller WL, Crabtree BF, Stange KC, Nutting PA, Jaén CR. Primary care practice development: a relationship-centered approach. Ann Fam Med 2010; 8(Suppl 1):S68-S79.

17. Landon BE, Gill JM, Antonelli RC, Rich EC. Prospects for rebuilding primary care using the patientcentered medical home. Health Aff (Millwood) 2010; 29(5):827-34.
18. Kilo CM, Wasson JH. Practice redesign and the patient-centered medical home: history, promises, and challenges. Health Aff (Millwood) 2010;29(5): 773-8.

19. Margolius D, Bodenheimer T. Transforming primary care: from past practice to the practice of the future. Health Aff (Millwood) 2010;29(5):779-84.

20. Lee TH, Bodenheimer T, Goroll AH, Starfield B, Treadway K. Perspective roundtable: redesigning primary care. N Engl J Med 2008;359(20):e24.

21. Sandy LG, Bodenheimer T, Pawlson LG, Starfield B. The political economy of U.S. primary care. Health Aff (Millwood) 2009;28(4):1136-45.

22. Appreciative Inquiry Commons. Available at: http:// appreciativeinquiry.case.edu/ Accessed 30 June 2010.

23. Cooperrider D, Sorensen PF Jr, Whitney D, Yeager $\mathrm{TF}$, eds. Appreciative inquiry: rethinking human organization toward a positive theory of change. Champaign, IL: Stipes Publishing, LLC; 2000.

24. Cooperrider DL, Whitney DK, Stavros JM. Appreciative inquiry handbook. 2nd ed. Brunswick, OH: Crown Custom Publishing, Inc.; 2008.

25. Loxterkamp D. A vow of connectedness: views from the road to Beaver's farm. Fam Med 2001;33(4): 244-7.

26. Loxterkamp D. Border crossings: on the boundary of the physician-patient relationship. J Am Board Fam Pract 1998;11(6):487-9.

27. Loxterkamp D. Being there: on the place of the family physician. J Am Board Fam Pract 1991;4(5): 354-60.

28. Stephens GG. The intellectual basis of family practice. Tucson, AZ: Winter Publishing Company; 1982.

29. Stange KC. The generalist approach. Ann Fam Med 2009;7(3):198-203.

30. Peabody FW. The care of the patient. JAMA 1927; 88:877-82.

31. Atlas SJ. Patient-physician connectedness and quality of primary care. Ann Int Med 2009;150:325-35.

32. Kon AA. The shared decision-making continuum. JAMA 2010;304(8):903-4.

33. Stephens GG. The personal touch: the physician as healer in modern society. J Kans Med Soc 1965; 66(5):237-49.

34. Loxterkamp D. A piece of my mind. Old men and the sea. JAMA 2010;304(1):18-9. 